\title{
Востребованность инженерного образования определяется успехами отрасли
}

Рассказывает президент Национального исследовательского университета "МИЭТ»Ю. А. Чаплыгин

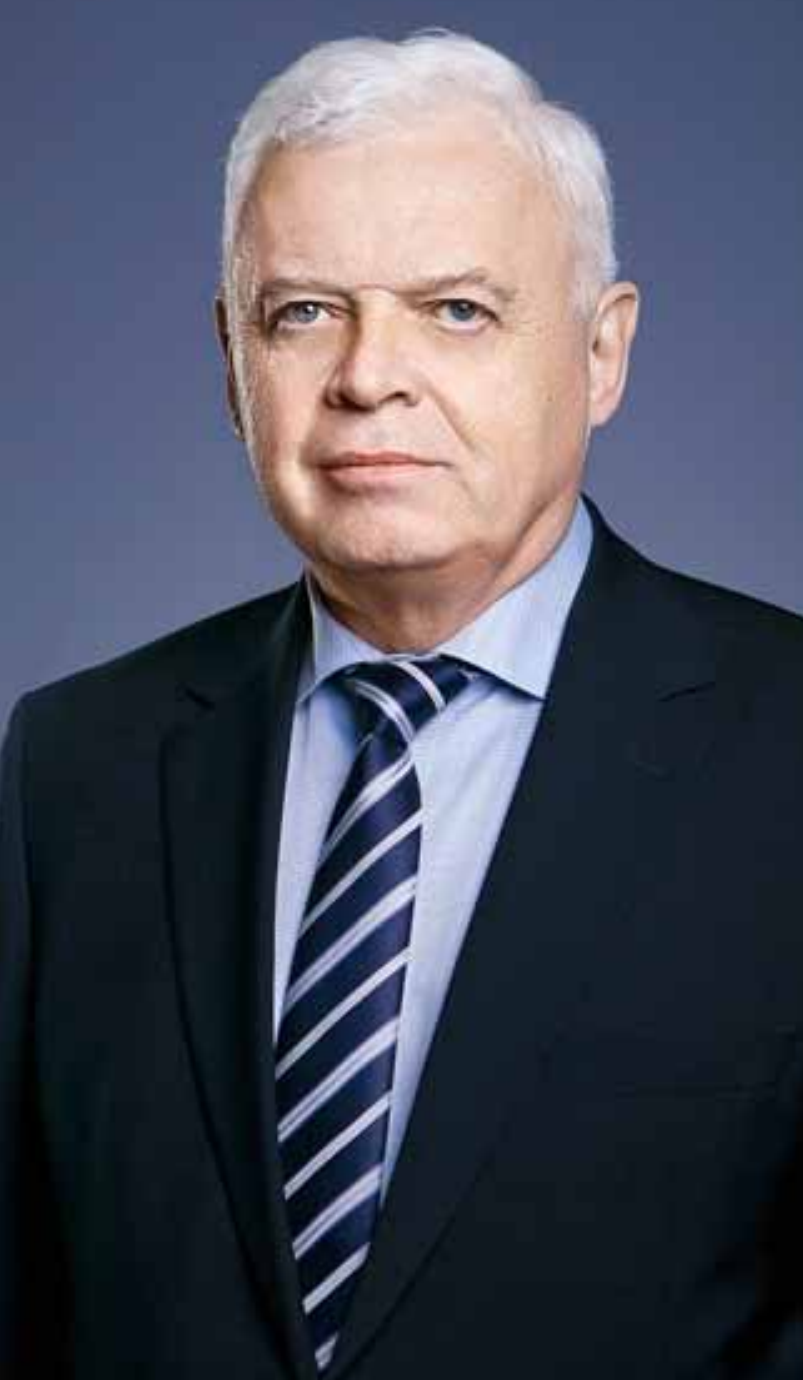

Национальный исследовательский университет "Московский институт электронной техники» - ведущий российский технический университет в области высоких технологий, высшее учебное заведение с полувековой историей и традициями. Интеграция образования, науки и промышленности делают МИЭТ лидером по подготовке специалистов в области микрои наноэлектроники, информационных технологий. Более 30 лет, вначале в качестве проректора, ректора, а с 2016 года в должности президента, в руководство университетом входит академик РАН, доктор технических наук Юрий Александрович Чаплыгин. С его именем связаны серьезные преобразования в вузе - проведена реорганизация кафедр и факультетов МИЭТ, начата подготовка студентов по ряду новых направлений, получил развитие учебно-научно-производственный комплекс МИЭТ, созданы учебные центры в партнерстве с ведущими международными компаниями, расширилось сотрудничество МИЭТ с институтами РАН. Недавно Юрий Александрович отметил 70-летний юбилей, он утвержден в должности президента МИЭТ сроком еще на 5 лет. Мы побеседовали с Юрием Александровичем об этапах становления вуза, современном состоянии российской системы высшего технического образования, перспективах развития МИЭТ. 
Юрий Александрович, разрешите поздравить вас с юбилеем, а также с недавним продлением полномочий президента МИэТ! Какой период вашей жизни вы вспоминаете чаще всего?

Прежде всего я хотел бы вспомнить достаточно короткий период своей жизни - учебу в 9-10-м классах физико-математической школы номер шесть г. Курска, прекрасных педагогов, которые дали нам знания, позволившие почти всему классу поступить в ведущие вузы страны. Мне это дало возможность поступить в МИЭТ - этот выбор определил мою жизнь на долгие годы, о чем я ни разу не пожалел.

Если сравнивать МИЭТ конца 1990-х, когда вы только вступили в должность ректора, с его нынешним состоянием, что вы назвали бы главным отличием?

В 1998 году, после дефолта, обстановка в стране была очень сложная. Конечно, и МИЭТ был в непростой ситуации, прежде всего с точки зрения финансов. Когда я стал ректором, а я пришел к руководству с новой командой, основная проблема состояла в том, чтобы вовремя оплатить счета за электричество, тепло, воду и т. д. К счастью этот период довольно быстро закончился. Правительством были приняты достаточно разумные решения, например, тем, кто выполнил текущие платежи, прощали предыдущие долги и т.д. Сегодня на первый план выходят совсем другие проблемы в первую очередь, проблемы качества образования

\section{Инновационный центр - визитная карточка нашего университета}

и научных исследований. В 2006-2007 годах МИЭТ принял участие в нацпроекте "Образование» и получил значительные средства на развитие, оснащение, создание учебников и учебно-методических пособий. Мы участвовали и в других программах. Еще одно значимое достижение - в 2010 году мы стали Национальным исследовательским университетом, что позволило оснастить лаборатории самым современным оборудованием. Кроме того, на базе МИЭТа был создан инновационный комплекс, идеи которого были заложены еще в конце 80-х годов прошлого века. Сегодня инновационный

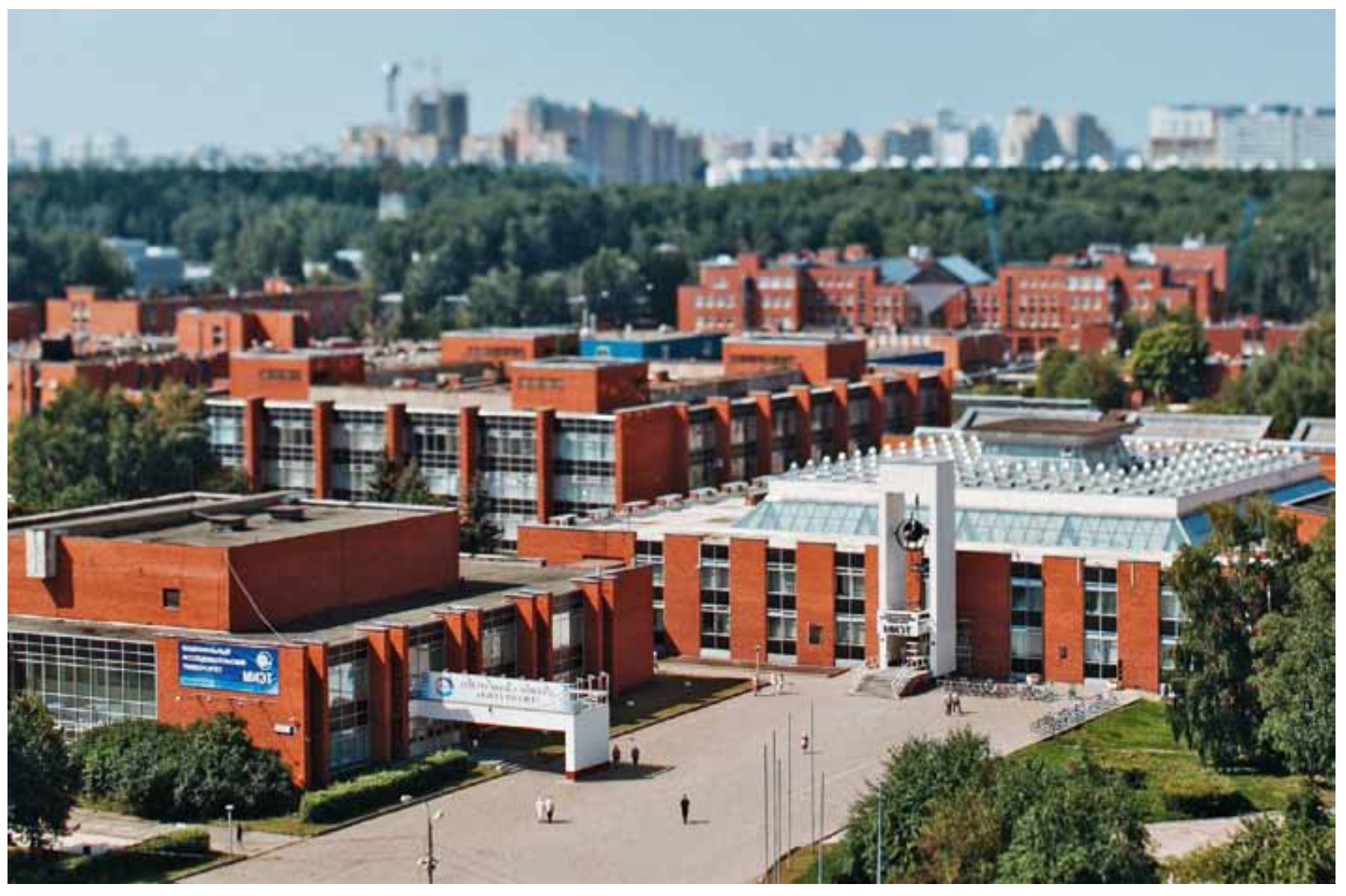




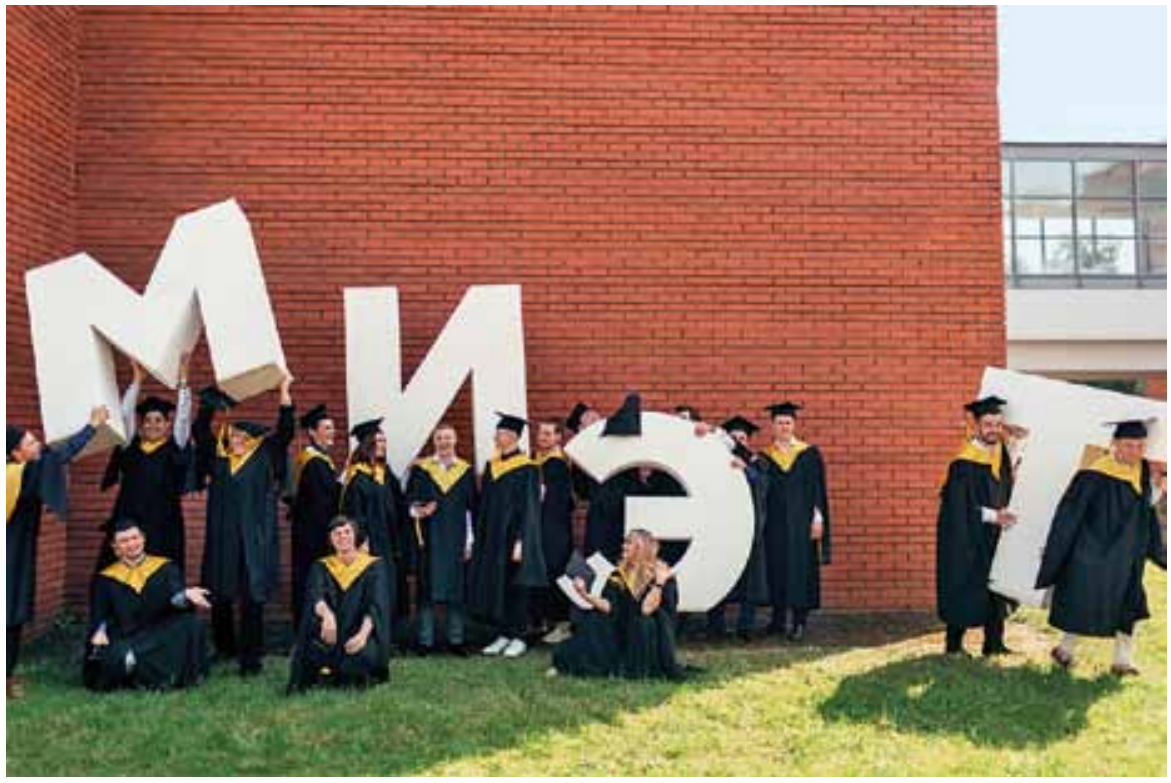

исследования или поменять тематику исследований. Это помогало преодолеть непростой период.

Вы вспоминали свои школьные годы, выбор профессии. С вашей точки зрения, абитуриенты, которые приходят в МИэТ сегодня, заинтересованы в получении высокотехнологичных профессий? И если у них такой интерес есть, способна ли сейчас отечественная промышленность этот интерес удовлетворить?

Конечно, если сравнивать с теми годами, когда мы поступали, то в то время естественно-научное и техническое образование было очень престижным. И наиболее

центр - визитная карточка нашего университета, в нем расположены высокотехнологичные компании, с которыми мы взаимодействуем и для которых мы готовим инженерные кадры

МИЭТ изначально создавался как вуз, тесно связанный с промышленностью, а в 90-х годах промышленность была в плачевном состоянии. Как удалось сохранить и поддержать научные исследования?

В МИЭТе в 90-е годы, несмотря на все проблемы, зарождались новые направления научной деятельности. Так, под руководством моего предшественника, Виталия Дмитриевича Вернера, создавался технологический центр, который впоследствии получил статус Государственного научного центра. То есть МИЭТ и в этот тяжелый период развивался.

\section{Задача студента во время обучения}

в вузе - забрать с собой максимально

возможный багаж знаний,
который может предложкить МИЭТ

Следует отметить, что в 90-е годы были и позитивные моменты, например, в Министерстве образования была создана программа «Конверсия», состоящая из 10-12 разделов, в том числе "Машиностроение", "Авиация и космос", "Энергетика" и т. д. МИЭТ возглавлял направление "Электроника». Эта научно-техническая программа серьезно помогла поддержать научные группы, позволив им продолжить подготовленные абитуриенты шли в технические вузы. Сейчас интерес к этому образованию постепенно возвращается, молодые люди понимают, что прогресс связан прежде всего с высокими технологиями. Показательно, что в последние годы отмечается рост среднего балла абитуриентов, поступающих в МИЭТ и в другие технические вузы. Ребята приходят достаточно подготовленные. Их задача во время обучения в вузе - забрать с собой максимально возможный багаж знаний, который может предложить МИЭТ. Большинство с этой задачей справляется, находят себя как в России, так и за рубежом. Хотелось бы, чтобы лучшие выпускники работали в своей стране.

\section{А страна готова дать им такую возможность сейчас?}

Есть компании, которые безусловно готовы. Хотелось бы, чтобы таких компаний было намного больше.

Каково ваше мнение о современном состоянии российской системы высшего технического образования в целом? Удовлетворяет ли она запросам промышленности, ориентированной на инновационные разработки?

Высшее техническое образование требует хороших знаний в области математики и физики. К сожалению, не могу сказать, что подготовка по этим предметам в школе становится лучше. Более того, все меньше школьников в рамках ЕГэ сдают физику. И Министерство науки и высшего образования РФ в какой-то степени идет на поводу этой тенденции, ведь по многим техническим направлениям 
сейчас можно сдавать информатику. Но дело в том, что информатику никогда не поздно изучить, этим можно заниматься и в вузе, и после его окончания. я, например, знаю много примеров того, как выпускники нашего физико-химического факультета становились программистами, хотя изначально они получили небольшой объем знаний по информатике. В то же время человек, который не получил достаточных знаний по физике в школе, не сможет успешно осваивать серьезные программы в вузе, что требуется для успешной учебы и работы в будущем. А если мы говорим об электронике, о высоких технологиях в целом, то без солидных знаний в области физики, химии, даже биологии, прогресса в этих областях не добиться. Поэтому, с моей точки зрения, необязательность физики в ЕГЭ в будущем негативно скажется на потенциале студентов технических вузов и инженеров.

Второй аспект касается не только технического образования. Когда мы учились, рабочая аудиторная неделя составляла 36 ч. Сейчас по стандартам - 27 ч. Я не уверен, что это правильно. Нельзя за это время дать столько же, сколько раньше, несмотря на то, что методики обучения значительно изменились, внедряется цифровизация и другие технологии. Тем не менее, мне кажется, что аудиторная нагрузка для студента могла бы быть сегодня повыше.

Техническое образование не может быть изолированным от промышленности. МИЭТ создавался в Зеленограде, где развивалась микроэлектроника и были теснейшие связи с научноисследовательскими институтами и производством по всем направлениям - разработка микросхем, материаловедение, электронное машиностроение и др. Подготовка в МИЭТе проводилась по всем этим направлениям, с восьмого семестра три дня в неделю студенты проходили производственную практику в НИИ и на предприятиях 3еленограда. Практически они два года учебы были тесно связаны с теми производственными подразделениями, куда потом приходили работать.

Когда я встречаюсь с представителями отрасли, я всегда искренне желаю им успеха, чтобы знания, полученные студентами, и научные исследования, проводимые в МИЭТе, были востребованы в промышленности. Когда отрасль развивается, растет спрос на кадры.

\section{МИЭТ создавался в Зеленограде, где развивалась микроэлектроника и были теснейшие связи с научно-исследовательскими институтами и производством по всем направлениям}

Прошлой осенью между МИЭТ и Отделением нанотехнологий и информационных технологий (ОНИТ) РАН было заключено соглашение о сотрудничестве. Что это дает университету и можно ли уже назвать какие-либо результаты этой совместной деятельности?

Сейчас вузы страны сдают заявки" по программе Минобрнауки по поддержке университетов «Приоритет-2030». Мы к этой программе тоже готовились и в рамках подготовки заключили соглашение с ОНИТ РАН, хотя давно активно взаимодействовали со многими институтами РАН. Сейчас рано говорить о каких-то конкретных результатах, но мы рассчитываем, что в рамках программы появится финансовая основа для расширения взаимодействия с институтами РАН как с точки зрения подготовки кадров, так и проведения совместных научных проектов.

Интервью было записано 3 августа 2021 года.

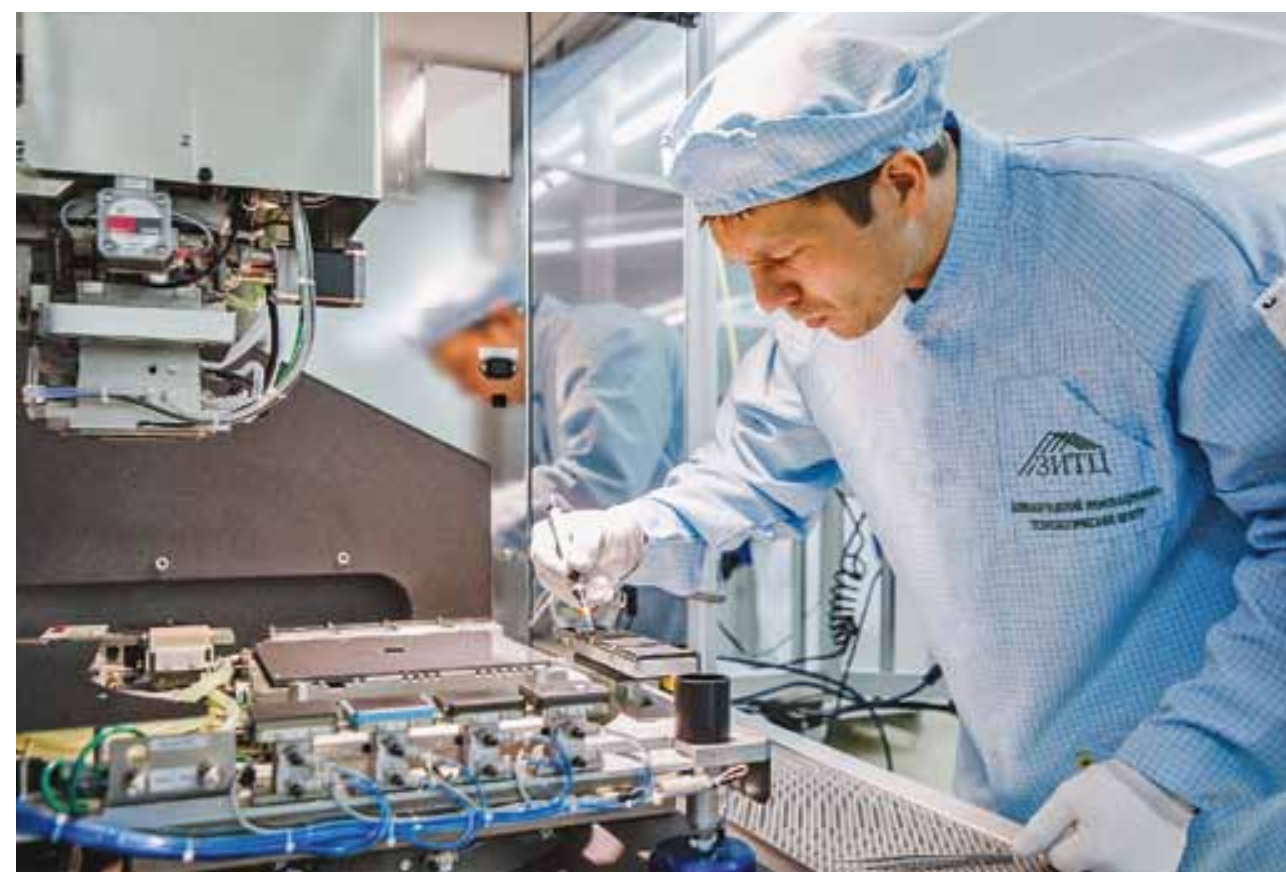


Можете ли вы обозначить направления, которые считаются приоритетными в рамках этого соглашения?

Это практически все направления, связанные с информационными технологиями и электрони кой, по которым мы готовим студентов и проводим исследования. Кроме того, мы участвуем в программе модернизации синхротрона в зеленограде.

\section{В рамках тех ограничений, в которых}

мы жкивем, реально внедрить технологию

$$
\begin{array}{r}
\text { 65-45 нм и, в последующем, } 28 \text { нм, } \\
\text { что позволит решать многие задачи } \\
\text { в промышиенности, машиностроении, } \\
\text { космической отрасли, энергетике и т.д. }
\end{array}
$$

Если говорить о микроэлектронике, какие направления вы считаете наиболее перспективными с точки зрения имеющегося научного потенциала и практических возможностей у российской промышленности?

Основные направления развития микроэлектроники изложены в Стратегии развития электронной отрасли до 2030 года. Очень хотелось бы, чтобы она была успешно завершена. Я считаю, что в рамках тех ограничений, в которых мы живем, реально внедрить технологию 65-45 нм и, в последующем, 28 нм, что позволит решать многие задачи в промышленности, машиностроении, космической отрасли, энергетике и т.д. Практическая реализация этих задач чрезвычайно важна.

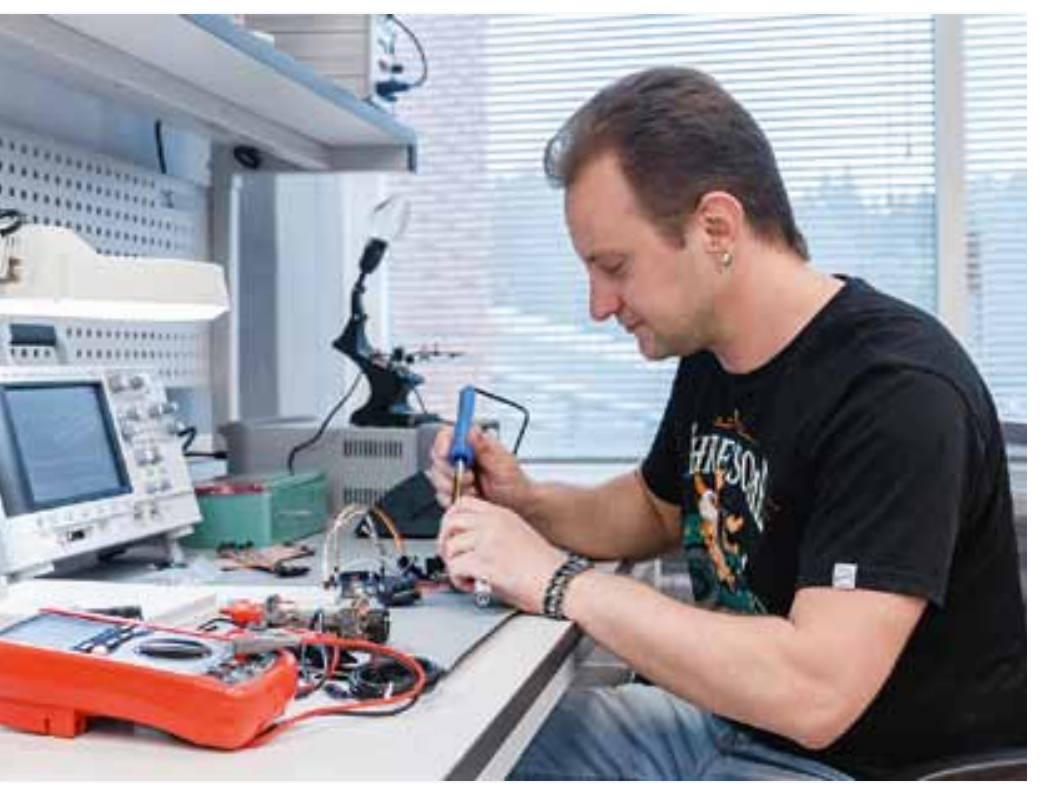

Технологию 28 нм сегодня часто выделяют в качестве приоритета. Связано ли это с технологическими проблемами внедрения более совершенных процессов или просто пока нет в них потребности?

Технологии 7 или 10 нм ориентированы в первую очередь на массовые потребительские продукты смартфоны, планшеты, компьютеры. Это те рынки, на которых нас сегодня практически нет. чтобы выйти на этот рынок нужно пройти длинный и трудный путь.

Сейчас вновь зазвучали слова по поводу физического предела уменьшения размеров транзистора, которые практически приблизились к размерам атома кремния. Могут ли российские ученые найти прорывные технологии, которые смогли бы преодолеть эту проблему? Как вы оцениваете перспективы России в этом отношении?

Пока сложно об этом говорить. Мы прикладываем значительные усилия в различных областях, в частности в области квантовых технологий. Другие страны также занимаются перспективными исследованиями, но там вкладывают в новые направления гораздо более значительные средства, поэтому пока российским ученым сложно найти свою нишу. Надеюсь, что им удастся это сделать

Чувствуете ли вы, что в России есть хорошая научная база в области фундаментальных наук, в частности в физике, которая поможет сделать прорыв в электронике?

Конечно, завтра или послезавтра прорыва не случится. Нужны исследования в таких областях, которые не только обеспечат качественный прорыв, но и будут технологичными. Например, много говорят о графенах, но пока они не внедрены в массовые технологические процессы. Поэтому нужны не только новые физические эффекты, но и их технологичность, возможность серийного производства. Этот аспект очень важен.

На базе МИЭТ создан центр компетенций НТИ по направлению "Технологии сенсорики". Насколько я знаю, эта тематика близка вам. Каково ваше мнение о том, на каком уровне находится это направление в России? Как вы оцениваете перспективы развития сенсорики в нашей стране?

Эта область развивается в России достаточно давно и успешно, здесь не требуются предельные 
технологические нормы, как в других применениях. Технологические возможности для реализации таких изделий в стране есть. В частности, достаточно интенсивно развивается технология МэМс. Считаю, что здесь у нас достаточно хорошие перспективы, позволяющие удовлетворить спрос промышленности. Я не вижу причин, по которым Россия может отстать от конкурентов в этой области. В МИЭТе мы уделяем этому направлению большое внимание.

Поделитесь, пожалуйста, вашим мнением о реализуемой в настоящее время Минпромторгом России Стратегии развития электронной промышленности РФ на период до 2030 года и инструментах ее реализации, таких как отраслевые консорциумы, сквозные проекты, меры поддержки в виде субсидий и т.п.

В этой стратегии много аспектов, связанных в том числе с созданием новых технологических мощностей. Безусловно, это важно и нужно. Но я бы хотел остановиться на другом моменте, который появился сравнительно недавно, - взаимоотношении Минпромторга России с высшей школой в том, что касается подготовки кадров для дизайн-центров электроники. В 2015 году по инициативе МИЭТ была создана ассоциация вузов, готовящих кадры для радиоэлектронной промышленности, в первую очередь, разработчиков электронной компонентной базы. К этой теме сейчас повышенный интерес. Вначале в ассоциации было 12 вузов, сейчас в ней около 30 участников. Мы очень активно взаимодействуем с Минпромторгом России, который выделил средства тем вузам, которые работают над проектами по созданию дизайн-центров как в области разработки интегральных схем, так и аппаратуры.

Мы знаем примеры таких стран, как например Финляндия, специалисты которой успешно разрабатывают электронику, а производят ее в других странах. Это не значит, что я предлагаю России пойти по этому пути, но в основе продукта всегда

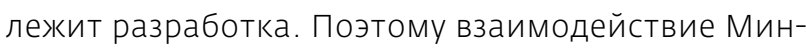
промторга России с вузами в рамках ассоциации по подготовке высококвалифицированных разработчиков для электронной отрасли очень важно для нашей страны

Какие первоочередные задачи сейчас ставятся в развитии МИЭт и каким вы лично хотели бы видеть университет в ближайшем будущем?

Хочу еще раз повторить тезис о том, что развитие вуза тесно связано с развитием промышленности. Если будет достигнут прогресс в отрасли, в частности как результат реализации «Программы-2030»,

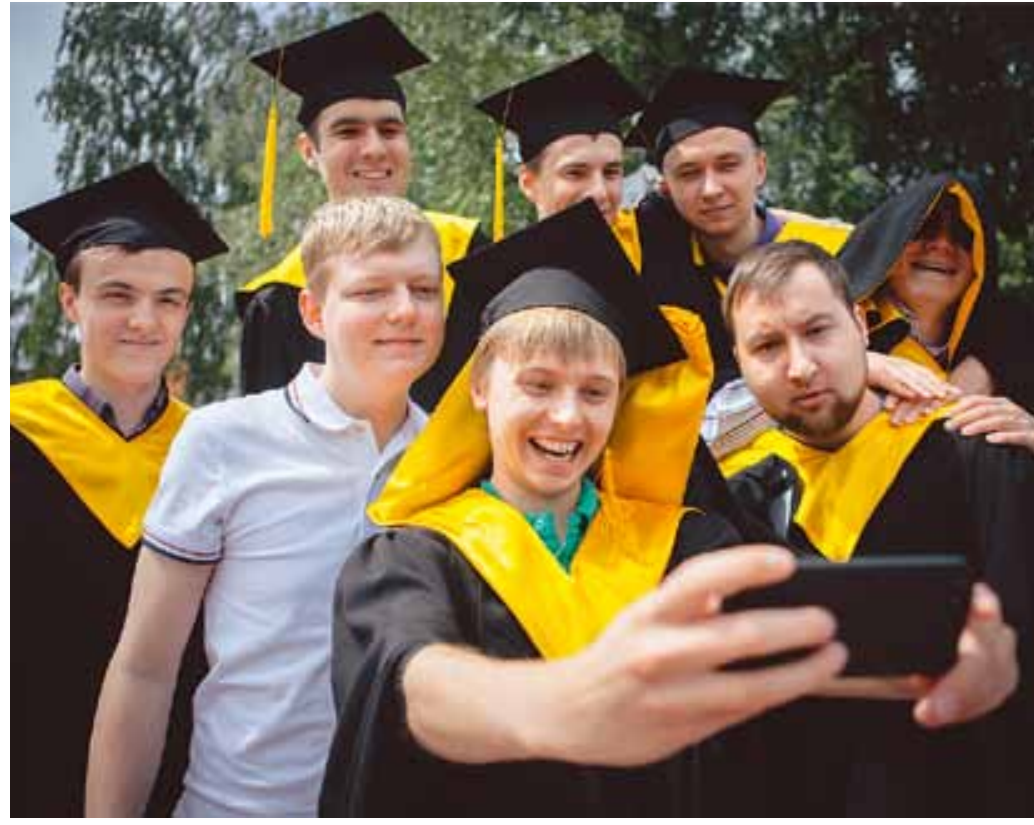

то будут востребованы выпускники вуза и научные исследования, которые проводит вуз. В заявке, которую подготовил МИЭТ для «Программы-2030»,

\section{Взаимодействие Минпромторга России с вузами в рамках ассощиащии по подготовке высококвалифищированных разработчиков для электронной отрасли очень важно для нашей страны}

отражено тесное взаимодействие с промышленностью, РАН, международными организациями. Хотелось бы, чтобы МИЭТ и дальше успешно развивал научные исследования, оснащался современным оборудованием, был среди мировых лидеров в области подготовки кадров в сфере электроники и информационных технологий. МИЭТ всегда готовил кадры для всей страны, поэтому насущная необходимость для нас - строительство общежития, без которого мы не можем удовлетворить всех желающих абитуриентов, которые приезжают к нам буквально со всех регионов Российской Федерации. Мы с оптимизмом смотрим в будущее, потому что уверены, что специалисты, подготовленные МИЭТом, будут востребованы в сфере высоких технологий!

\section{Спасибо за интересный рассказ.}

С Ю. А. Чаплыгиным беседовап Ю. С. Ковалевский. материал подготовлен В. Б. Ежовым. 
TEХНОСФЕРА

РЕКЛАМНО-ИЗДАТЕЛЬСКИЙ ЦЕНТР

\section{0\% ГАРАНТИЯ ПОЛУЧЕНИЯ ВСЕХ НОМЕРОВ}

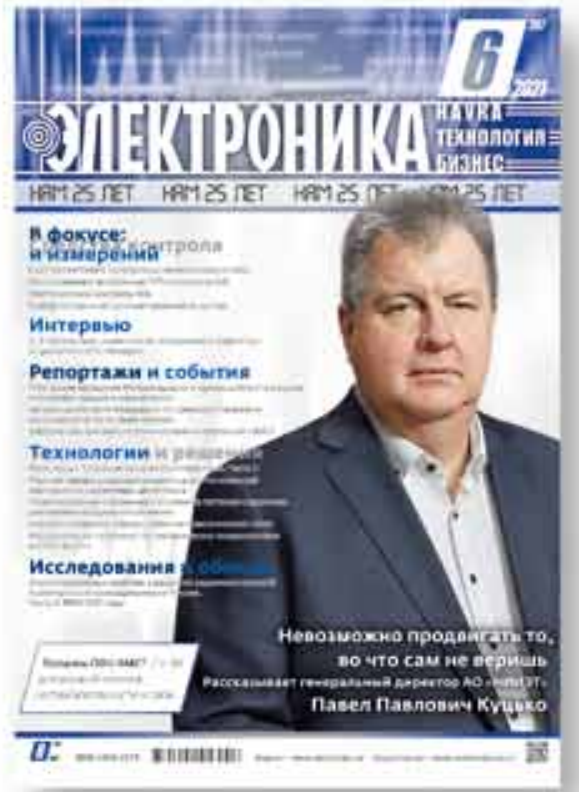

Стоимость 2200 р. за номер

Периодичность: 10 номеров в год

www.electronics.ru

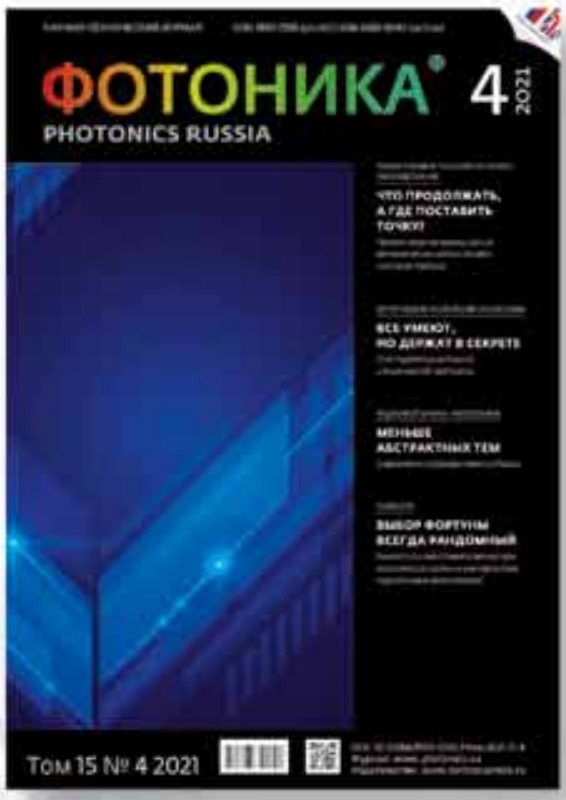

Стоимость 1430 p. за номер

Периодичность: 8 номеров в год www.photonics.su

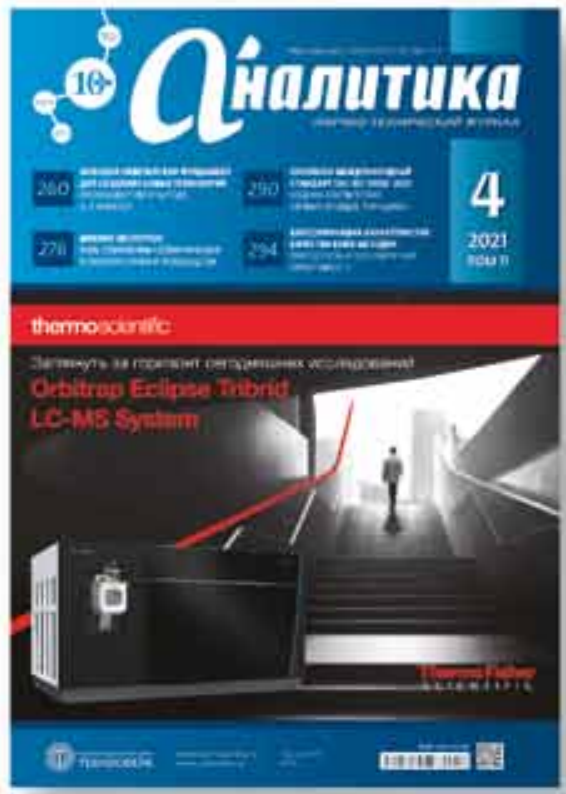

Стоимость 1430 р. за номер

Периодичность: 6 номеров в год www.j-analytics.ru

\section{ПОДПИСКА НА ХУРНАЛЬ}

\section{www.technosphera.ru}

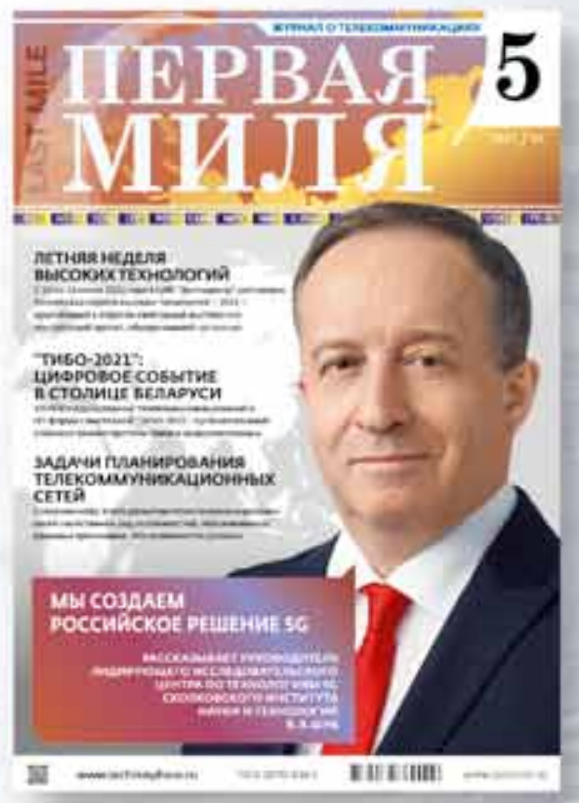

Стоимость 1056 p. за номер

Периодичность: 8 номеров в год www.lastmile.su

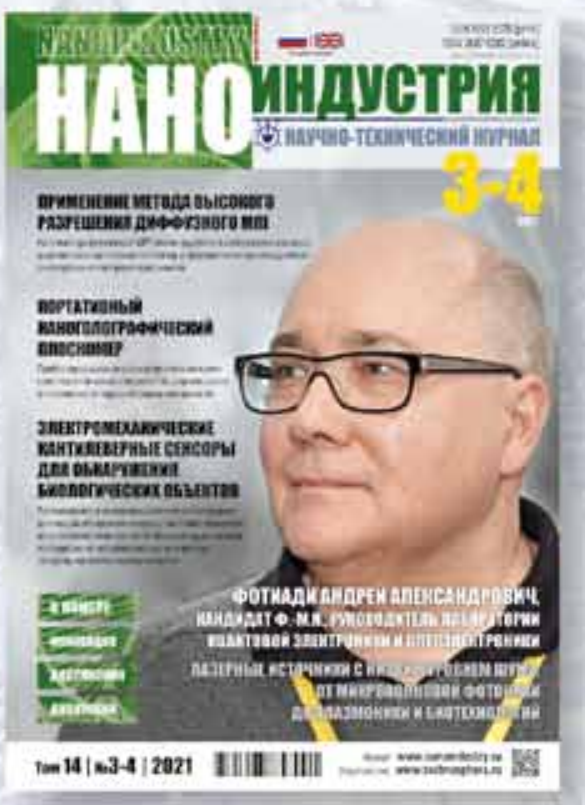

Стоимость 1287 р. за номер

Периодичность: 8 номеров в год

www.nanoindustry.su

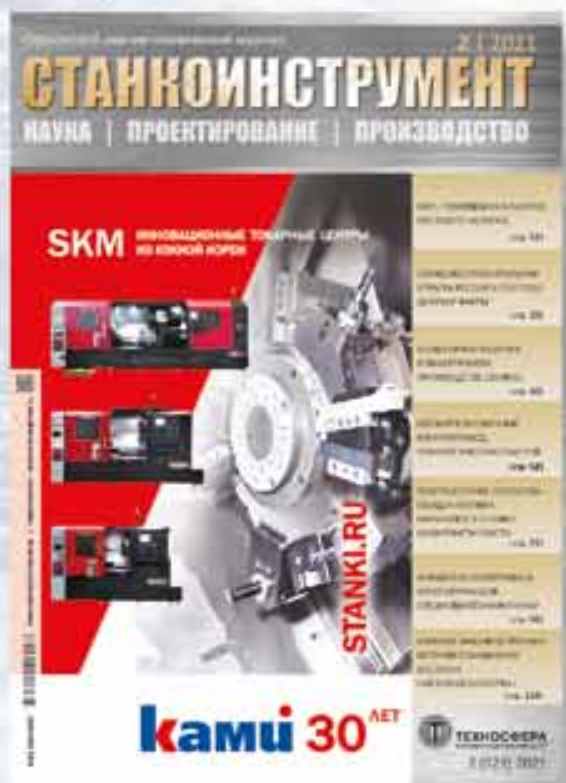

Стоимость 1716 p. за номер

Периодичность: 4 номера в год www.stankoinstrument.su 